\title{
Effect of Personal Variables of College Student of Rajkot City on their Emotional Maturity
}

\author{
Tarlika L. Zalavadia ${ }^{1}$, Harsukh G. Bhut ${ }^{2}$
}

\section{ABSTRACT}

The study was designed to investigate the impact of certain socio personal variables on the College Student Emotional Maturity of Rajkot City. The sample consisted of 240 College Student selected randomly from Rajkot City. Emotional Maturity Scale (EMS) of Romapal (1988) was used. Data were analysis by ' $t$ ' test. Results revealed that there exists a No significant difference was found between the College Student gender, Type of family, Family members and Education faculty their Emotional Maturity.

Keywords: Emotional Maturity and College Student

Emotional Maturity is not only the effective determinant of personality pattern but also helps to control the growth of individual development. The concept mature emotional behavior at any level is that which reflects the fruits of normal emotional development. It is a stage, which is very essential in human life. One of the major aims of any good educational programmer is to help the learner to gain emotional maturity.

Emotional maturity defined as, "A process in which the personality is continually striving for greater sense of emotional health, both intra-psychically and intra-personally". In brief emotional maturity can be called as the process of impulse control through the agency of "self" or "ego". According to Menninger (1999), emotional maturity includes the ability to deal constructively with reality. Emotional maturity is a process in which the personality is continuously striving for greater sense of emotional health, both intra physically and interpersonally.

Goleman (1995), we have two minds, one that thinks and one that feels, these two fundamentally different ways of knowing, interact to construct our mental life. The rational mind is the mode of comprehension we are typically conscious of more prominent in awareness, thoughtful, able to ponder and reflect. The emotional mind is impulsive and powerful and sometimes illogical. These two minds operate in harmony with each other, most of times feelings are essential to

\footnotetext{
${ }^{1}$ Associate Professor, Department of Psychology, Smt.R.R.Patel Mahila Arts \& Commerce College, Rajkot Gujarat-India

${ }^{2}$ Ph.D. Research Scholar, Department of Psychology, Saurashtra University, Rajkot - Gujarat-India *Responding Author

(C) 2016 I T Zalavadia, H Bhut; licensee IJIP. This is an Open Access Research distributed under the terms of the Creative Commons Attribution License (http://creativecommons.org/licenses/by/2.0), which permits unrestricted use, distribution, and reproduction in any Medium, provided the original work is properly cited.
} 
thought, and most of the times thoughts to feeling. But when passions surge the balance tips: it is not just I.Q., but emotional intelligence that matters. Goleman rightly points out that, "It is not that we want to do away with emotions and put reason in its place, but instead find an intelligent balance of two"

To give meaning to the concept of emotional maturity as applied to children, it would be necessary to take into account maturity at various developmental levels leading up to mature adult level. Even at adult level, there should be gradation, as the science of germination probably will find that there are pronounced differences between mature adult of 25 and mature adult of 45 that are just truly developmental in nature.

Prof Y. Singh (1990) "Emotional maturity is not only the effective determinant of personality pattern but also helps to control the growth of an adolescent's development. A person who is able to keep his emotions under control, to brook delay and to suffer without self-pity might still be emotionally stunned”. So emotionally mature person will have more satisfaction in life; he will be satisfied with what he is and have a balance between his head and heart.

K. Subbarayan \& G. Visanathan (2011) concluded that the sex, community and family type did not play any role in emotional maturity of college students. It also revealed that majority of college students are extremely unstable. Sunil Kumar (2014) discloses that a significant correlation exists between emotional maturity and family relationship. From the review of different sources it was found that no comprehensive study was conducted on the university students and the investigator makes an effort to identify the level of emotional maturity in university students, keeping in view their level of education.

\section{OBJECTIVE}

- The main aim of this study was to investigate the impact of the personal variables of Rajkot City College Student on their Emotional Maturity.

\section{METHOD}

\section{Samples}

The sample size was 240 College Student, comprising of College Student from Rajkot City. The collected information can be managed carefully and more accurately.

\section{Tools}

\section{Emotional Maturity Scale}

Emotional maturity scale developed by Roma Pal (1988) was used to measure emotional maturity the scale contains 40 items with totally agree, neutral, generally, disagree and totally disagree. Response alternative the responses were marked 5,4,3,2 and 1 respectively and from the responses we had to select only one response in every sentence. 5 for tick mark totally agree, 4 for tick mark agree, 3 for tick mark neutral, 2 for tick mark disagree and 1 for tick mark totally disagree. The maximum possible score is 200 and minimum is 40.Scoring pattern shows that more score indicates less emotional maturity. The less score in the scale indicates good (more) 
emotional maturity. The reliability score of emotional maturity scale comes to 0.84 , derived by the split half method, obtained from the sample of 200 students. The researcher of the present research has found out the reliability score as 0.81 , by using split half technique on the sample of 50 students.

\section{Procedure}

In this research test were administrated individually as well as on young people, which collecting data for the study before attempting the questionnaire the subjects were requested to read the instruction carefully and follow them in true spirits. While the data collection was completed then ' $\mathrm{t}$ ' was used to check result.

\section{RESULT AND DISCUSSION}

Table: t-test comparison based on Emotional Maturity of Rajkot City College Student with respect to Gender, Types of family, Family members and Education faculty

\begin{tabular}{|l|l|l|l|l|l|}
\hline Variable & N & SD & Mean & SED & t \\
\hline $\begin{array}{l}\text { Gender } \\
\text { Male }\end{array}$ & 105 & 6.53 & 31.17 & & \\
\hline $\begin{array}{l}\text { Female } \\
\text { Types of family }\end{array}$ & 135 & 6.21 & 29.97 & 0.81 & $1.48 \mathrm{NS}$ \\
\hline Joint Family & 165 & 7.89 & 30.29 & & $0.82 \mathrm{NS}$ \\
\hline Nuclear Family & 75 & 4.37 & 30.93 & 0.78 & \\
\hline Family members & & & & & $0.31 \mathrm{NS}$ \\
\hline 5 to below & 126 & 7.06 & 30.62 & & \\
\hline 5 to above & 114 & 6.48 & 30.35 & 0.86 & \\
\hline $\begin{array}{l}\text { Education } \\
\text { faculty }\end{array}$ & & & & & \\
\hline Arts/Commerce & 156 & 6.54 & 30.32 & & \\
\hline Science/All & 84 & 6.06 & 30.82 & 0.83 & \\
\hline & & & & & \\
\hline
\end{tabular}

NS = Not Significant

In order to know the difference between groups ' $t$ ' is calculated after in present study, ' $t$ ' values on shown in table From these findings it can be said that ' $t$ ' value of means obtained for the Emotional Maturity of Male and Female College Student is 1.48 which is not show significant. Not Supporting the existing results, earlier studies with Swenson (1961) and Jeffer et al (1961) found differences in emotional maturity among male and female college students. The ' $t$ ' value of scores of Emotional Maturity of joint and nuclear family College Student is 0.82 which is also showing not significant. The ' $t$ ' value of scores of Emotional Maturity of 5 to below and 5 to above family members College Student is 0.31 which does not show significant. The ' $t$ ' value of scores of Emotional Maturity of arts/commerce and science/all faculty College Student is 0.60. 
This value is not significant. Following finding support this result no statistically significant differences in relation to Emotional Maturity between Rajkot City College Student.

\section{CONCLUSION}

There is no significant found between the Emotional Maturity and Gender, types of family, family members, education faculty Rajkot City College Student.

\section{REFERENCES}

Aleem, S. (2005, july). Emotional Stability among College Youth. Journal of Indian Academy of Applied Psychology, 31, 100-102.

Hangal, S, \& Aminabhavi, A. (2007).Self- Concept, Emotional Maturity and Achievement Motivation of the Adolescent Children of Employed Mothers and Homemakers. Journal of Indian Academy of Applied Psychology, 33(1), 103-110.

Kasirajan, V (2015). A study on interpersonal intelligence and emotional maturity of higher secondary 1 biology students in relation to their achievement in tirunelveli City.

Kaur, M. (2001). A study of emotional maturity of adolescents in relation to intelligence, academic achievement and environmental catalysts. Ph.D Thesis, Punjab University, Chandigarh.

Kour, J., \& Arora, B. (2014). Coping styles among teachers trainees in relation to emotional maturity. IMPACT: International Journal of Research in Humanities, Arts and Literature, 2(4), 29-34.

Nasreen taj and Krishan murathy V.S Emotional Maturity and Level of Anxiety among Rural College Students. http://www.academia.edu

Singhvi,Mahendra Kumar (2015). Development patterns of psychosocial maturity

Subbarayan, K., \& Visvanathan, G. (2011). A study on emotional maturity of college students. Recent Research in Science \& Technology, 3(1),153-155. 